\title{
Perancangan Aplikasi Pembelajaran Pengenalan Huruf Dan Angka Berbasis Augmented Reality
}

\author{
Nurul Huda ${ }^{[1]}$, Fitri Purwaningtias ${ }^{[2]}$ \\ Universitas Bina Darma, Jln.Jenderal Ahmad Yani No.02. Palembang ${ }^{[1][2]}$ \\ Nurul_huda@binadarma.ac.id ${ }^{[1]}$, Fitri.purwaningtias@binadarma.ac.id ${ }^{[2]}$
}

\begin{abstract}
Abstrak - Dengan berkembangnya teknologi informasi, pembelajaran pengenalan huruf dan angka dapat dilakukan dengan menggunakan media komputer, laptop, maupun smartphone. Metode pembelajaran seperti ini dapat membuat anak-anak lebih semangat dalam belajar karena selama ini metode pembelajaran yang dikenalkan kepada siswa hanya bersifat konvensional. Apalagi dengan menggunakan Teknologi Augmented Reality yang merupakan sebuah istilah untuk lingkungan yang menggabungkan dunia nyata dan dunia virtual yang dibuat oleh komputer sehingga batas antara keduanya menjadi sangat tipis. Sistem ini lebih dekat kepada lingkungan nyata (real). Karena itu, reality lebih diutamakan pada sistem ini. Adapun metode yang digunakan dalam perancangan pembelajaran ini yaitu metode waterfall yang nantinya akan menghasilkan suatu perancangan aplikasi pembelajaran pengenalan huruf dan angka berbasis Augmented Reality.
\end{abstract}

Kata Kunci- Pengenalan huruf dan Angka, Augmented Reality, Waterfall

\section{Pendahuluan}

\section{A. Latar Belakang}

Augmented Reality merupakan sebuah teknologi yang melibatkan overlay grafis komputer pada dunia nyata, dimana dunia maya tiga dimensi bisa dibawa ke lingkungan dunia nyata secara real-time. Tidak seperti realitas maya (VirtualReality) yang sepenuhnya menggantikan kenyataan,

realitas tertambah sekedar menambahkan atau melengkapi kenyataan.

Augmented Reality merupakan upaya untuk menggabungkan dunia nyata dan dunia maya yang dibuat melalui komputer sehingga batas antara keduanya menjadi sangat tipis dan memproyeksikannya secara real-time serta

\section{bersifat interaktif.}

Selama ini siswa hanya dikenalkan dengan metode pembelajaran secara konvensional saja sedangkan zaman sudah berubah secara drastis dimana komputer, laptop bahkan smartphone pun sudah meraja lela dan anak-anak zaman sekarang pun sudah mengenal smartphone dengan canggihnya dan sudah saatnya metode pembelajaran harus mengikuti perkembangan zaman. Oleh karena itu, dengan menggunakan teknologi yang semakin canggih dapat mendukung dunia pendidikan juga dalam memajukan pendidikan di Indonesia
Salah satunya adalah teknologi Augmented Reality yang merupakan terobosan baru dalam dunia global. Teknologi augmented biasanya hanya digunakan untuk permainan game saja dan disini saya ingin mencoba untuk melakukan penelitian membuat suatu aplikasi pengenalan huruf dan angka berbasis augmented reality dimana anak-anak dapat belajar mengenal huruf dan angka dengan tampilan animasi 3 dimensi dimana teknologi ini menggabungkan antara dunia nyata dan dunia virtual. Sama halnya seperti siswa SD IT Mutiara Sunnah dimana metode pembelajarannya masih konvensional jadi dengan adanya aplikasi pembelajaran berbasis augmented reality ini nantinya diharapkan para siswa dapat belajar lebih semangat dan lebih dapat mengingat huruf dan angka dengan cepat dan tepat.

\section{B. Permasalahan}

"Bagaimana Merancang suatu Aplikasi Pengenalan Huruf Dan Angka Berbasis Augmented Reality?"

\section{Tujuan Penelitian}

Menghasilkan suatu rancangan atau disain Aplikasi Pengenalan Huruf Dan Angka Berbasis Augmented Reality.

\section{TINJAUAN PUSTAKA}

\section{A. Pembelajaran}

Menurut Daryanto (2013:181), pembelajaran merupakan kegiatan belajar mengajar yang melibatkan siswa dan guru dengan menggunakan berbagai sumber belajar, baik dalam situasi kelas maupun di luar kelas.

\section{B. Augmented Reality}

Azuma mendefinisikan Augmented reality sebagai penggabungan benda - benda nyata dan maya di lingkungan nyata, berjalan secara interaktif dalam waktu nyata dan terdapat integrasi antarbenda dalam tiga dimensi, yaitu benda maya terintegrasi dalam dunia nyata. Penggabungan benda nyata dan maya dimungkinkan dengan teknologi tampilan yang sesuai, interaktivitas dimungkinkan melalui perangkat-perangkat input tertentu, dan integrasi yang baik memerlukan penjejakan yang efektif.

Tujuan utama dari Augmented Reality adalah menciptakan lingkungan baru dengan menggabungkan interaktivitas 
lingkungan nyata dan maya sehingga pengguna merasa bahwa lingkungan yang diciptakan adalah nyata. Dengan kata lain, pengguna merasa tidak ada perbedaan yang dirasakan antara AR denganapa yang mereka lihat atau rasakan di lingkungan nyata. Dengan bantuan teknologi AR (seperti visi komputasi dan pengenalan objek)lingkungan nyata disekitar akan dapat berintegrasi dalam bentuk digital (virtual). Informasi tentang objek dan lingkungan disekitar kita dapat ditambahkan kedalam sistem AR yang kemudian informasi tersebut ditampilkan diatas layar dunia nyata secara real-time seolaholah informasi tersebut adalah nyata agar pemahaman penggunanya menjadi jelas

\section{Metode Marker Based Tracking}

Marker Based Tracking adalah salah satu metode yang dapat digunakan dalam pengembangan teknologi augmented reality.

Metode ini bekerja dengan cara mengenali dan mengidentifikasi pola pada sebuah marker untuk memunculkan sebuah objek virtual ke lingkungan nyata. Marker adalah sebuah pola berbentuk persegi berwarna hitam putih dengan sisi tebal berwarna hitam.

\section{Android}

Android adalah sistem operasi untuk telepon seluler yang berbasis Linux. Android menyediakan platform terbuka bagi para pengembang buat menciptakan aplikasi mereka sendiri untuk digunakan oleh bermacam peranti bergerak. Di dunia ini terdapat dua jenis distributor sistem operasi

Android. Pertama yang mendapat dukungan penuh dari Google atau Google Mail Services (GMS) dan kedua adalah yang benar-benar bebas distribusinya tanpa dukungan langsung Google atau dikenal sebagai Open Handset Distribution (OHD).

\section{E. Unity $3 D$}

Unity 3D merupakan sebuah tools yang terintegrasi yang dapat digunakan untuk membuat bentuk obyek 3 dimensi pada sebuah permainan atau bisa juga digunakan untuk membuat animasi 3D real time seperti aplikasi augmented realit. Salah satu kelebihan Unity 3D adalah multiple platform karena aplikasi yang dihasilkan dengan software ini dapat dijalankan pada Windows, Mac, Xbox 360, Playstation 3, Wii, iPhone, iPad serta Android. Dengan menggunakan

Software ini, kita bisa membuat sebuah game,aplikasi augmented reality, visualisasi arsitektur serta aplikasi-aplikasi lain dengan menggunakan bahasa pemrograman JAVA SCRIPT, CS SCRIPT (C\#) dan BOO SCRIPT. Jika dibandingkan tools-tools lain yang serupa unity lebih memenuhi dan melayani keinginan pengembang karena fitur fitur yang ada di unity 3D lebih lengkap dan mudah dimengerti.

\section{F. Blender}

Blender merupakan sebuah software open source yang digunakan untuk pemodelan multimedia seperti pemodelan 3 dimensi. Blender memiliki fitur-fitur yang cukup lengkap untuk memudahkan penggunanya dalam merancang objek 3 dimensi.

\section{G. Adobe Photoshop}

Aplikasi adobe photoshop adalah program komputer yang merupakan perangkat lunak atau software yang di gunakan untuk pengolahan gambar/foto, dapat di gunakan untuk memanipulasi foto sehingga hasil foto lebih menarik. Aplikasi Adobe Photoshop pada dasarnya merupakan aplikasi pengolah gambar, namun seringkali pula ia digunakan untuk mengubah tampilan suatu objek, misalnya teks atau tulisan. Adobe Photoshop bukan pengolah kata, tapi ia dapat membuat beragam efek menarik untuk mempercantik tampilan gambar dan teks.

\section{H. Vuforia}

Vuforia merupakan SDK yang disediakan Qualcomm untuk memudahkan para pengembang aplikasi-aplikasi Android dan iOS yang menerapkan teknologi augmented reality. Vuforia memiliki banyak kemampuan yang ditawarkan, salah satunya adalah image target. Image target disini maksudnya vuforia dapat mengenali target berupa gambar (tidak harus berupa QRCode). Namun tidak semua gambar bisa dijadikan target, vuforia menyediakanT arget Management System (TMS) yang akan menilai baik buruknya sebuah gambar yang digunakan. Penilaian itu dihitung dari jumlah bintang yang dihasilkan (mulai dari 1 bintang hingga 5 bintang), semakin banyak bintang maka kualitas gambar yang digunakan juga semakin baik.

\section{Animasi 3D (Tiga Dimensi)}

Tiga Dimensi, biasanya digunakan dalam penanganan grafis. 3D secara umum merujuk pada kemampuan dari sebuah video card (link). Saat ini video card menggunakan variasi dari instruksi-instruksi yang ditanamkan dalam video card itu sendiri (bukan berasal dari software) untuk mencapai hasil grafik yang lebih realistis dalam memainkan game komputer. Perkembangan teknologi dan dunia komputer membuat teknik pembuatan animasi 3D semakin berkembang dan maju pesat. Animasi 3D adalah perkembangan dari animasi 2D. Dengan animasi 3D, karakter yang diperlihatkan semakin hidup dan nyata, mendekati wujud aslinya.

\section{Metodologi Penelitian}

\section{A. Metode Pengumpulan Data}

\section{1) Studi Lapangan}

Merupakan teknik pengumpulan data dengan mengadakan penelitian secara langsung pada lokasi 
penelitian, dalam hal ini lokasi yang dijadikan sebagai objek penelitian adalah SD IT Mutiara Sunnah palembang.

\section{2) Metode Interview atau Wawancara}

Merupakan suatu metode pengumpulan data melalui tatap muka dan tanya jawab langsung antara pewawancara dengan responden (sumber data). Dalam hal ini, peneliti melakukan wawancara dengan kepala sekolah pada SD IT Mutiara Sunnah palembang.

\section{3) Observasi}

Merupakan suatu metodepengumpulan data dengan cara mengamati secara langsung kegiatan yang sedang berlangsung pada SD IT Mutiara Sunnah palembang.

\section{4) Studi Pustaka}

Metode ini dilakukan dengan cara menggunakan beberapa data-data dan buku untuk referensi dalam melakukan pengumpulan data penulisan penelitian ini dan dokumentasi yang ada di SD IT Mutiara Sunnah palembang.

\section{B. Metode Pengembangan Sistem}

Menurut Rosa dan Shalahuddin (2011:26) Metode pengembangan sistem yang digunakan adalah metode SDLC air terjun atau (waterfall) atau sering disebut juga model sekuensial linier (sequential linear) atau alur hidup klasik (classic life cycle). Metode air terjun ini menyediakan pendekatan alur hidup perangkat lunak secara sekuensial atau terurut dimulai dari analisis, desain, pengkodean, pengujian, dan tahap pendukung (support). Berikut adalah gambar metode air terjun:

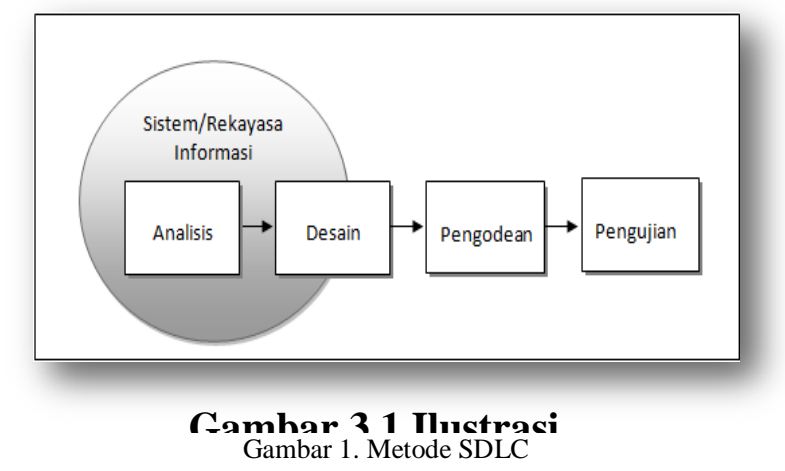

\section{1) Analisis Kebutuhan Perangkat Lunak}

Proses pengumpulam kebutuhan dilakukan secara intensif untuk menspesifikasikan kebutuhan perangkat lunak agar dapat dipahami perangkat lunak sepeti apa yang dibutuhkan oleh user. Spesifikasi kebutuhan perangkat lunak pada tahap ini perlu untuk didokumentasikan.

\section{2) Desain}

Desain perangkat lunak adalah proses multilangkah yang fokus pada desain pembuatan program perangkat lunak termasuk struktur data, arsitektur perangkat lunak, representasi antarmuka, dan prosedur pengodean. Tahap ini mentranslasi kebutuhan perangkat lunak dari tahap analisis kebutuhan ke representasi desain agar dapat diimplementasikan menjadi program pada tahap selanjutnya. Desain perangkat lunak yang dihasilkan pada tahap ini juga perlu didokumentasikan.

\section{3) Pembuatan Kode Program}

Desain harus ditranslasikan ke dalam program perangkat lunak. Hasil dari tahap ini adalah program komputer sesuai dengan desain yang telah dibuat pada tahap desain.

\section{4) Pengujian}

Pengujuan fokus pada perangkat lunak secara dari segi lojik dan fungsional dan memastikan bahwa semua bagian sudah diuji. Hal ini dilakukan untuk meminimalisir kesalahan (error) dan memastikan keuaran yang dihasilkan sesuai dengan yang diinginkan.

\section{5) Pendukung (Support) atau Pemeliharaan} (Maintenance)

Tidak menutup kemungkinan sebuah perangkat lunak mengalami perubahan ketika sudah dikirimkan ke user. Perubahan itu bisa da karena adanya kesalahan yang muncul dan tidak terdeteksi saat pengujian atau perangkat lunak harus beradaptasi dengan lingkungan baru. Tahap pendukung atau pemeliharaan dapat mengulangi proses pengembangan mulai dari analisis spesifikasi untuk perubahan perangkat lunak yang sudah ada, tapi tidak untuk membuat perangkat lunak baru.

\section{HASIL DAN PEMBAHASAN}

\section{A. Use Case Diagram}

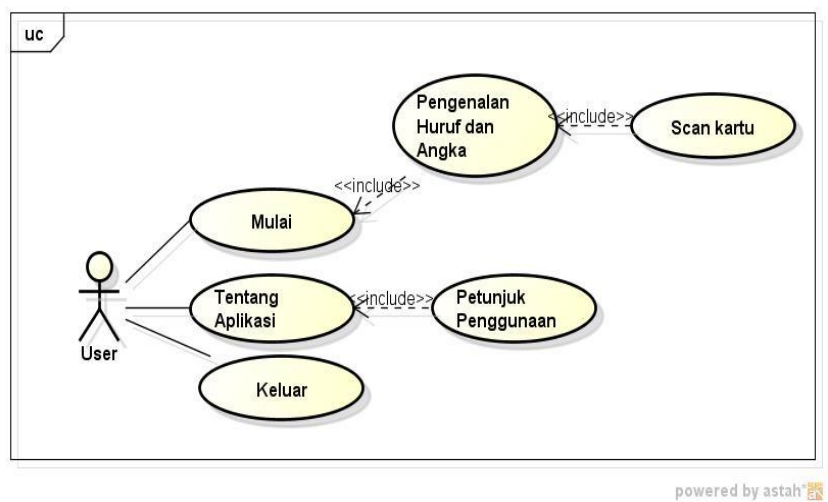

Gambar 2. Diagram Usecase 
B. Activity Diagram

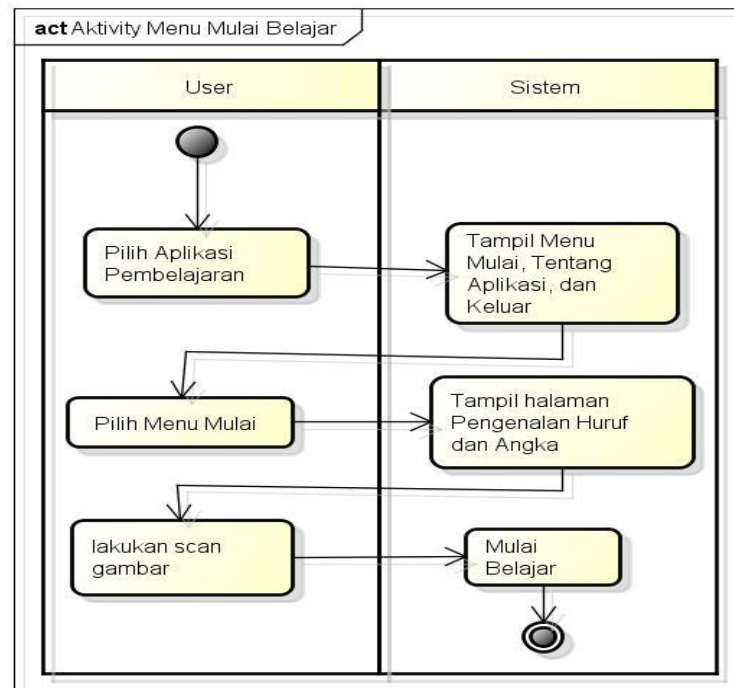

Gambar 3. Diagram Aktivity

C. Halaman Menu Utama

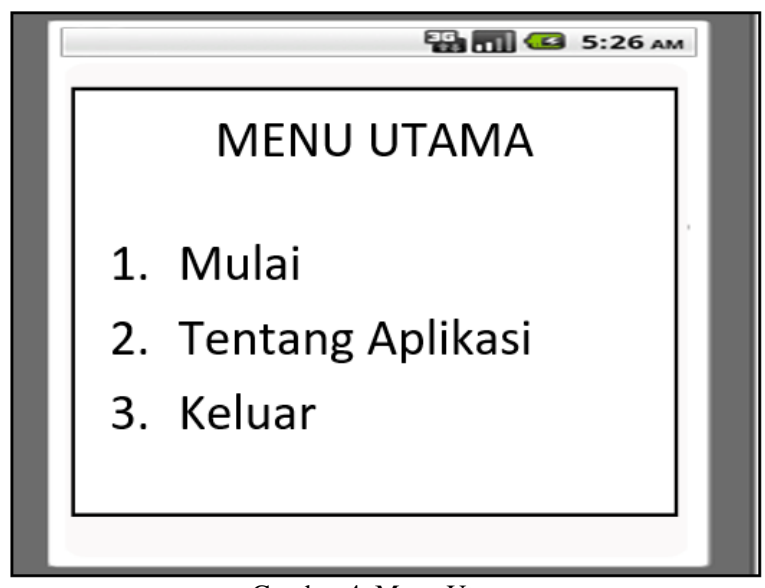

Gambar 4. Menu Utama

\section{Halaman Mulai}

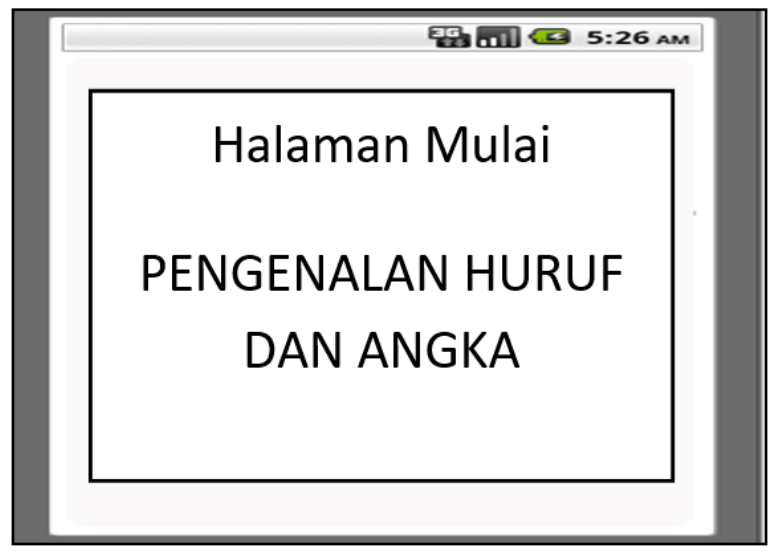

Gambar 5. Halaman Mulai
E. Halaman Scan Gambar/Marker

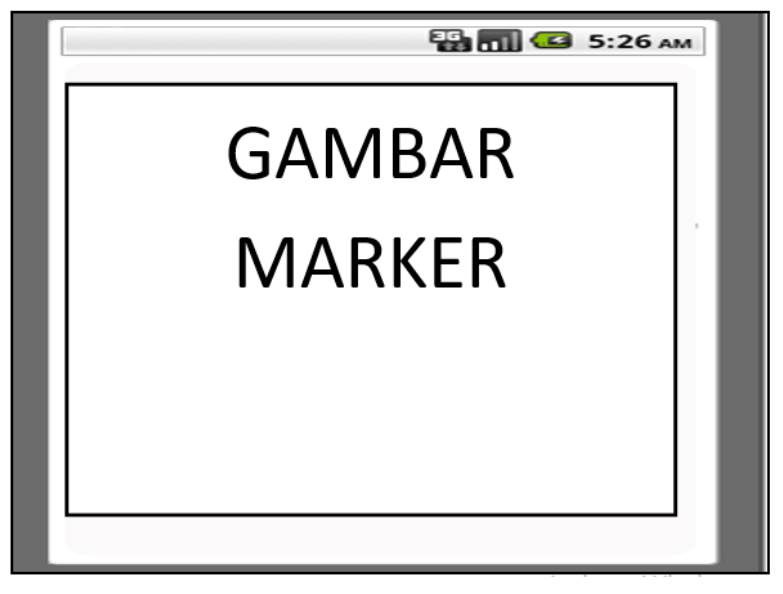

Gambar 6. Halaman Scan Gambar

F. Halaman Tentang Aplikasi

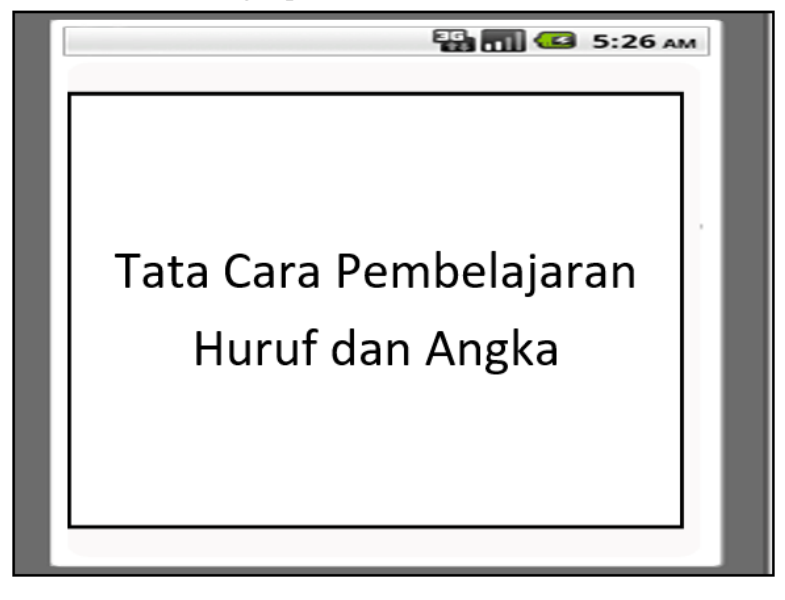

Gambar 7. Halaman Tentang Aplikasi

\section{PENUTUP}

A. Kesimpulan

- Dengan mengimplementasikan media pembelajaran augmented reality ini para siswa khususnya SD Mutiara Sunnah dapat lebih termotivasi dalam belajar matematika.

- Dengan metode pembelajaran ini para siswa dapat lebih mengenal huruf dan angka.

\section{B. Saran}

Media Pembelajaran ini hanya sebatas interface saja dan dapat lebih di kembangkan lagi dengan membuatkan aplikasinya dan juga dengan berbagai mata pelajaran lainnya 


\section{DAFTAR PUSTAKA}

[1] Azuma, ronaldo T. (August 1997). A Survey of Augmented Reality. Presence: Teleoperators and Virtual Environments.

[2] Haller, Michael \& Billinghurst, Mark. 2010. Emerging technologies of Augmented Reality: Interfaces and Design Idea Group Publishing.

[3] Nazaruddin, Safaat H. 2012 (Edisi Revisi). Pemograman Aplikasi Mobile Smartphone dan Tablet PC berbasis Android. Informatika. Bandung.

[4] Rifai, Muhammad. Penerapan Teknologi Augmented Reality Pada Aplikasi Katalog Rumah Berbasis Android

[5] Rosa A.S. dan Shalahuddin, M. 2011. "Modul Pembelajaran Rekayasa Perangkat Lunak". Penerbit Modula, Bandung

[6] Santoso, Apri. "Rancang Bangun Aplikasi Pembelajaran Organ Tubuh Berbasis Augmented Reality".

[7] S. P. Julia, Ernawati, A. Erlansari.Rancang Bangun Aplikasi Layanan Berbasis Lokasi Dengan Penerapan Augmented Reality Menggunakan Metode Markerless Berbasis Android. E-Jurnal Teknik Informatika, Universitas Bengkulu. 2011.

[8] Elvrilla, Septri, “Augmented Reality Panduan Belajar Sholat Berdasarkan Buku
[9] Teks Belajar Sholat Menggunakan Android," Skripsi Teknik Informatika Universitas Gunadarma, Jakarta, 2011

[10] A. P. Basworo. Desain dan Implementasi Augmented Reality Berbasis Web pada Aplikasi Furniture Shopping Manager Sebagai Alat Bantu Belanja Online . Fakultas Teknologi Informasi dan Komunikasi Universitas Semarang. 2012

[11] A. T. Ricky, G. Mardi. Visualisasi Stand Pameran Berbasis Augmented Reality Dengan Menggunakan Openspace3d. Universitas Gunadarma Jakarta. 2013

[12] Y. P. Mukhlis, F. Yuli, E. P. Yusapril. Aplikasi Augmented Reality Pembelajaran Organ Pernapasan Manusia Pada Smartphone Android. Teknik Informatika Politeknik Caltex Riau. 2012

[13] H. P. Taufik, S. W. Barandi, S. H. Karen. Augmented Reality sebagai Model Data Sistem Informasi Geografis. [E-Jurnal] Diakses pada 10 Juni 2015, dari http://www.academia.edu

[14] M. Rifa'i, T. Listyorini, A. Latubessy.Penerapan Teknologi Augmented Reality Pada Aplikasi Katalog Rumah Berbasis Android . Teknik Informatika Universitas Muria Kudus. 2014

[15] Suharso, A. Model Pembelajaran Interaktif Bangun Ruang 3d Berbasis Augmented Reality. Teknik Informatika Universitas Singaperbangsa Karawang. 2012. 